\title{
Effects of Rice Fiber on Fecal Weight, Apparent Digestibility of Energy, Nitrogen and Fat, and Degradation of Neutral Detergent Fiber in Young Men
}

\author{
Hiroko MiYOSHI, Toyoko OKUDA, Yuriko OI, \\ and Hideo $\mathrm{KOISHI}^{1}$ \\ Department of Food and Nutrition, Faculty of the Science of Living, \\ Osaka City University, Sugimoto, Sumiyoshi-ku, \\ Osaka 558, Japan
}

(Received April 5, 1986)

\begin{abstract}
Summary The effects of rice fiber on fecal weight, transit time, frequency of defecations, digestibility of nutrients and blood status were investigated in 5 healthy young men. Each of them consumed a brown rice diet and then a polished rice diet for 2 weeks respectively. Both diets contained $1.2 \mathrm{~g}$ protein per $\mathrm{kg}$ body weight. The brown rice diet contained 2 times as much dietary fiber as the polished rice diet. When they consumed the brown rice diet, it showed an increase of fecal weight and decrease of digestibility of energy, nitrogen and fat. Nitrogen balance was not significantly different and kept zero balance on both diets. Concentration of plasma cholesterol was not significantly different. The results suggest that rice fiber produced an increase in fecal weight, which is assumed to be effective in preventing colonic disease in advanced countries and does not affect plasma lipid level.
\end{abstract}

Key Words brown rice, dietary fiber, fecal weight, digestibility of energy, nitrogen and fat

The role of dietary fiber in nutrition is a topic of current interest. Research in epidemiology has demonstrated that dietary fiber is related to prevention of colon cancer, diverticular disease, diabetes mellitus and coronary heart disease (1-5). Especially, the role of dietary fiber from cereal sources on colonic function seems to be of importance (6).

Considerable research has been carried out to find a logical explanation for the role of dietary fiber in prevention of these diseases. A good many experimental animals have been used in these investigations. There are a few experiments with human subjects under controlled conditions. Bread is eaten widely among people in Western countries, since wheat fiber is the most popular unpurified fiber. When

1 三好弘子, 奥田豊子, 尾井百合子, 小石秀夫 
intake of wheat fiber increases, fecal weight increases, intestinal transit time shortens and absorption of energy, nitrogen, fat, and minerals decreases (7-10). Rice is grown widely in East Asian countries including Japan. Rice is a major cereal and consequently the major source of fiber in most East Asian countries. It ranks third as cereal food grain in the world. Rice is eaten by boiling it as grains. There are few experiments on brown rice $(11,12)$. Therefore, we studied the effects of rice fiber as the main fiber source in the diet. We compared adult men when they consumed mainly brown rice, with when they consumed mainly polished rice each for 2 weeks with respect to fecal weight, apparent digestibility of energy, nitrogen and fat, apparent degradation of neutral detergent fiber (NDF), nitrogen balance and plasma cholesterol level.

\section{METHODS}

We used 5 healthy male subjects (means \pm standard deviations: age $20.2 \pm 1.6$ years, height $169 \pm 7 \mathrm{~cm}$, weight $55.8 \pm 8.3 \mathrm{~kg}$ ). They showed normal values in urinary tests and hematological tests. The experimental protocol was approved by the Committee of Osaka City Univ. on the Use of Humans as Experimental subjects. The full nature and purpose of the experiment were explained to these subjects and their consent was obtained before the study. They were housed in the University's metabolic wards, being allowed to continue their normal daily routines.

Diet. An experimental period of 33 days was divided into three parts. The subjects were each fed on a pre-test diet for 5 days and then on 2 experimental diets which lasted for 14 days each. Throughout the study they consumed the same foodstuffs except for the type of rice. The ingredients of the diets $/ 60 \mathrm{~kg}$ body weight are shown in Table 1. The subjects were given $550 \mathrm{~g} / 60 \mathrm{~kg}$ body weight of brown rice (cultivar: Kiyonishiki) in the initial experimental part, and in the following part they were given $600 \mathrm{~g} / 60 \mathrm{~kg}$ body weight of polished rice (cultivar: Kiyonishiki). The amount of all foodstuffs consumed by each subject except powdered starch syrup was calculated in proportion to their body weight. They ate the brown rice and polished rice as boiled rice. Each diet provided $1.2 \mathrm{~g}$ protein $/ \mathrm{kg}$ of body weight and $45 \mathrm{kcal} / \mathrm{kg}$ of body weight. Energy intake was adjusted to keep body weight constant with powdered starch syrup. Dietary fiber intake of $550 \mathrm{~g}$ brown rice was $22.2 \mathrm{~g} \mathrm{NDF}(4.0 \mathrm{~g} \mathrm{NDF} / 100 \mathrm{~g})$ and that of $600 \mathrm{~g}$ polished rice was $6.9 \mathrm{~g}$ NDF $(1.1 \mathrm{~g}$ $\mathrm{NDF} / 100 \mathrm{~g}$ ). The total amount of NDF in the brown rice diet provided $30.1 \mathrm{~g} \mathrm{NDF} /$ $60 \mathrm{~kg}$ body weight and that in the polished rice diet provided $14.8 \mathrm{~g} \mathrm{NDF} / 60 \mathrm{~kg}$ body weight. These values were measured in our laboratory (13). The brown rice diet contained 2 times the amount of NDF as compared with the polished rice diet. The diets were complemented by a mixture of vitamins and minerals to supply the daily allowance. Calculated nutrient values of the diets are shown in Table 1.

Collection and analysis of samples. Individual urine samples were collected in urine bottles with hydrochloric acid as a preservative for a $24-\mathrm{h}$ period throughout the study. One experimental part was divided into three sections. Feces were marked 
Table 1. Experimental diet (g per $60 \mathrm{~kg}$ body weight per day).

All foodstuffs, except powdered starch syrup, consumed by each subject were calculated in proportion to their body weight. Calculated from data in standard tables of food composition in Japan.

\begin{tabular}{lcc} 
& $\begin{array}{c}\text { Pre test diet } \\
\text { PR }\end{array}$ & BR \\
\hline Polished rice & 600 & - \\
Brown rice & - & 550 \\
Cucumber & 80 & 80 \\
Tomatoes & 50 & 50 \\
Head lettuce & 30 & 30 \\
Cabbage & 50 & 50 \\
Onion & 100 & 100 \\
Sweet pepper & 10 & 10 \\
Cheese & 10 & 10 \\
Egg & 90 & 90 \\
Chicken (sasami) & 50 & 50 \\
Skim milk & 5 & 5 \\
Soy sauce & 5 & 5 \\
NaCl & 5 & 5 \\
Corn oil & 20 & 20 \\
Rice oil & 9 & - \\
Sugar & 9 & 20 \\
Powdered starch syrup & - & 64 \\
Vitamin tablet & 1 & 1 \\
Mineral mix & 14.8 & 3 \\
Energy (kcal) & $1^{\mathrm{b}}$ & 22 \\
Protein & & 71 \\
Lipid & 2,761 & 50 \\
NDF (from rice) & 71 & 22.2 \\
$\quad$ (total) & 50 & \\
\hline
\end{tabular}

$\mathrm{PR}$, polished rice diet; $\mathrm{BR}$, brown rice diet; NDF, neutral detergent fiber. ${ }^{\mathrm{a}} \mathrm{A}$ vitamin tablet (courtesy of Takeda Chemical Industries, Ltd.) contained 1,000 IU retinol palmitate, $100 \mathrm{IU}$ ergocalciferol, $5 \mathrm{mg}$ fursulthiamine, $2 \mathrm{mg}$ riboflavin, $3 \mathrm{mg}$ pyridoxine hydrochloride, $25 \mathrm{mg}$ nicotinamide, $5 \mu \mathrm{g}$ cyanocobalamine, $75 \mathrm{mg}$ ascorbic acid, $5 \mathrm{mg}$ tocopherol acetate, $15 \mathrm{mg}$ calcium pantothenate, $46.8 \mathrm{mg}$ precipitated calcium carbonate and $34 \mathrm{mg}$ dibasic calcium phosphate. ${ }^{\mathrm{b}}$ One tablet/person. ${ }^{\mathrm{c}}$ One hundred grams of mineral mixtue contained $39.25 \mathrm{~g} \mathrm{KHCO}_{3}, 25.11 \mathrm{~g} \mathrm{CaCO}_{3}, 21.74 \mathrm{~g} \mathrm{KH}_{2} \mathrm{PO}_{4}, 10.78 \mathrm{~g}$ $\mathrm{MgSO}_{4} \cdot 7 \mathrm{H}_{2} \mathrm{O}, \quad 2.91 \mathrm{~g} \quad \mathrm{FeC}_{6} \mathrm{H}_{5} \mathrm{O}_{7} \cdot 6 \mathrm{H}_{2} \mathrm{O}, \quad 0.1314 \mathrm{~g} \quad \mathrm{CuSO}_{4} \cdot 5 \mathrm{H}_{2} \mathrm{O}, \quad 0.0366 \mathrm{~g}$ $\mathrm{MnSO}_{4} \cdot 4 \mathrm{H}_{2} \mathrm{O}, 0.0316 \mathrm{~g} \mathrm{ZnCl}_{2}$ and $0.0067 \mathrm{~g} \mathrm{KI} .{ }^{\mathrm{d}} \mathrm{g} /$ person.

by giving the subjects $3 \mathrm{~g}$ of charcoal powder and collected in each section. Transit time was computed as the time from ingestion of the marker until most of the color had appeared in the feces. Weight of dry feces were measured by freeze-drying. 
Food, urine and fecal samples were frozen for analysis. Blood was withdrawn from the antecubital vein before breakfast at the end of each experimental part. The plasma was separated by centrifugation. Energy in samples were measured by a bomb calorimeter. Nitrogen was determined by the semi-micro Kjeldahl method. Fat was extracted by the method of Folch(14). NDF in food and feces was determined by modification of Van Soest(13). Total cholesterol in plasma was determined by the enzymatic method (15). HDL cholesterol was determined by the enzymatic method (16). Hematocrit was determined by high-speed centrifugation in a capillary tube. Hemoglobin was determined by the international standard method. Plasma protein was determined by the biuret reaction method and albumin by the bromcresol green method. The measurements of blood status were checked by control serum (Ortho Diagnostics Inc., Raritan, N. J. 08869). Nitrogen balance was calculated from intake and urinary and fecal excretion. Data were analyzed statistically by using the student's $t$ test for significant difference between the two diets interval.

\section{RESULTS}

Table 2 shows transit time, frequency of defecation and fecal weight for 5 men who consumed a polished rice diet and a brown rice diet. Transit time and frequency of defecation did not differ significantly in both diets. Weight of wet feces, that of dry feces and water in feces significantly increased when they ate the brown rice diet. These were about twice as much as when they ate the polished rice diet. But, percentage of water in feces from the brown rice diet was not significantly different from that of the polished rice diet.

Table 3 shows intake, excretion and apparent digestibility of energy, nitrogen and fat. When they consumed the brown rice diet, energy of fecal excretion was twice and especially the fat was 5 times more than that when they consumed the polished rice diet. Difference in nitrogen was not significant between the two diets.

Table 2. Transit time, frequency of defecations and fecal weight for 5 men consuming a polished rice diet and a brown rice diet.

\begin{tabular}{lcc}
\hline & PR & BR \\
\hline Transit time (h) & $28.1 \pm 0.6$ & $27.1 \pm 0.5$ \\
Frequency of defecations/day & $1.11 \pm 0.09$ & $0.99 \pm 0.08$ \\
Weight of wet feces (g/day) & $125.4 \pm 50.4$ & $237.8 \pm 45.0^{*}$ \\
Weight of dry feces (g/day) & $28.5 \pm 6.9$ & $54.4 \pm 10.0^{*}$ \\
Water in feces (g) & $97.0 \pm 43.6$ & $183.4 \pm 35.1^{*}$ \\
Water in feces (\%) & $76.2 \pm 3.9$ & $77.1 \pm 0.5$ \\
\hline
\end{tabular}

$\mathrm{PR}$, polished rice diet; $\mathrm{BR}$, brown rice diet. Means $\pm \mathrm{SD} .{ }^{*}$ is significantly different from $\operatorname{PR}(p<0.05)$. 
Table 3. Excretion and apparent digestibility of energy, nitrogen, and fat of 5 men consuming polished rice diet and brown rice diet.

\begin{tabular}{lcc}
\hline & PR & BR \\
\hline Energy & & \\
Intake (kcal/day) & $2,477 \pm 350$ & $2,580 \pm 395$ \\
Fecal excretion (kcal/day) & $139.8 \pm 26.8$ & $278.1 \pm 66.8^{*}$ \\
Urinary excretion (kcal/day) & $71.5 \pm 8.4$ & $65.2 \pm 8.6$ \\
Apparent digestibility (\%) & $94.4 \pm 0.5$ & $89.3 \pm 1.2^{*}$ \\
Nitrogen & & \\
Intake (g N/day) & $9.91 \pm 1.61$ & $9.27 \pm 1.42$ \\
Fecal excretion (g N/day) & $2.03 \pm 0.38$ & $2.54 \pm 0.47$ \\
Urinary excretion (g N/day) & $8.34 \pm 1.09$ & $6.89 \pm 0.70$ \\
Balance (g N/day) & $-0.38 \pm 0.19$ & $0.02 \pm 0.27$ \\
Apparent digestibility (\%) & $79.6 \pm 1.3$ & $72.7 \pm 2.1 *$ \\
Fat & & \\
Intake (g/day) & $46.62 \pm 7.58$ & $46.28 \pm 7.09$ \\
Fecal excretion (g/day) & $2.47 \pm 0.52$ & $12.06 \pm 2.38^{*}$ \\
Apparent digestibility (\%) & $94.7 \pm 0.7$ & $74.1 \pm 1.7^{*}$ \\
\hline
\end{tabular}

$\mathrm{PR}$, polished rice diet; $\mathrm{BR}$, brown rice diet. Means $\pm \mathrm{SD} .{ }^{*}$ is significantly different from PR $(p<0.05)$.

Table 4. Blood status.

\begin{tabular}{lccc}
\hline & & PR & BR \\
\hline $\mathrm{Ht}$ & $\%$ & $44.4 \pm 2.8$ & $42.1 \pm 2.5$ \\
$\mathrm{Hb}$ & $\mathrm{g} / 100 \mathrm{ml}$ & $14.9 \pm 1.0$ & $14.5 \pm 1.1$ \\
Plasma & & & \\
Protein & $\mathrm{g} / 100 \mathrm{ml}$ & $6.63 \pm 0.40$ & $6.50 \pm 0.15$ \\
Albumin & $\mathrm{g} / 100 \mathrm{ml}$ & $4.68 \pm 0.15$ & $4.56 \pm 0.10$ \\
Urea & $\mathrm{mg} \mathrm{N} / 100 \mathrm{ml}$ & $12.3 \pm 1.8$ & $11.5 \pm 1.4$ \\
Total cholesterol & $\mathrm{mg} / 100 \mathrm{ml}$ & $136 \pm 39$ & $126 \pm 30$ \\
HDL-cholesterol & $\mathrm{mg} / 100 \mathrm{ml}$ & $34.5 \pm 3.2$ & $31.8 \pm 4.9$ \\
\hline
\end{tabular}

$\mathrm{PR}$, polished rice diet; $\mathrm{BR}$, brown rice diet. Means $\pm \mathrm{SD}$.

Energy and nitrogen in urinary excretion were not significantly different between the two diets. Apparent digestibility of energy, nitrogen and fat was significantly lower when the brown rice diet was consumed than when the polished rice diet was consumed. Nitrogen balance did not differ significantly between the two diets.

Table 4 shows blood status at the end of each experimental part. There was no significant difference between when the brown rice diet was consumed and when the polished rice diet was consumed. Concentration of total cholesterol and that of 
Table 5. Degradation of dietary fiber (NDF) for 5 men consuming polished rice diet and brown rice diet.

\begin{tabular}{lcc}
\hline & PR & BR \\
\hline Intake (g NDF/day) & $13.7 \pm 2.2$ & $27.9 \pm 4.3^{*}$ \\
Fecal (g NDF/g dry feces) & $0.330 \pm 0.031$ & $0.355 \pm 0.067$ \\
(g NDF/day) & $9.1 \pm 2.0$ & $19.4 \pm 7.2^{*}$ \\
Degradation $(\%)$ & $33.6 \pm 8.6$ & $32.0 \pm 15.6$ \\
\hline
\end{tabular}

$\mathrm{PR}$, polished rice diet; $\mathrm{BR}$, brown rice diet. Means $\pm \mathrm{SD} .{ }^{*}$ is significantly different from PR $(p<0.05)$.

HDL cholesterol in plasma were not significantly different between the two diets.

Table 5 shows the fate of neutral detergent fiber (NDF). Fecal concentration of $\mathrm{NDF}$ (g NDF/g dry feces) was the same in the two diets. But the total excretion of NDF in feces was significantly greater when the brown rice diet was consumed than when the polished rice diet was consumed, reflecting increased fecal weight. The degradation rate of NDF was the same in the two diets.

\section{DISCUSSION}

The fiber from rice in the diet produced some of the same effects that have been reported for addition of wheat bran to the diet (7-10). These effects occurred mainly in the small intestine and colon, and then decreased digestibility of nutrients.

Cummings reported effects on the human large intestine (6). Metabolism of fiber in the human large intestine differed, depending on the source of fiber. When the fiber from cereal, even rice or wheat was consumed, similar effects were expected. Actually, as wheat is eaten as bread, wheat fibers are powdered. But subjects in this experiment ate brown rice as whole grains, which was boiled, although it seemed that both might have similar effects.

Significant increase of fecal weight was observed by many investigators (17). Dokkum et al. reported that fecal weight increased twice when wheat fiber increased from $9 \mathrm{~g} \mathrm{NDF} /$ day to $35 \mathrm{~g} \mathrm{NDF} /$ day (10). This result agrees well with our result. In their experiment, they measured fecal VFA (volatile fatty acids). They presumed that an increase of fecal weight depended on the production of VFA in the colon. It seemed that the VFA had an osmotic action, which might partly account for the observed increase in fecal weight on increased fiber intake.

In our experiment, undigested dietary fiber on the brown rice diet was $19 \mathrm{~g}$ $\mathrm{NDF} /$ day. The matrix of the fiber particles was responsible for the action of sponge (18), which seems to be an important determining factor of the observed increase in fecal weight. And the increased fecal weight could also be accounted for by the increased bacterial mass (as a result of fiber fermentation) which might hold water as well (19). Degradation of fiber in the intestine took place in an anaerobic 
process, and then large amounts of fiber intake might affect the pattern of intestinal flora $(20)$.

The results of our study on brown rice were similar to those of another investigation which used vegetables and fruits (21). The loss of energy, nitrogen and fat in feces was greater with a high fiber diet than with a low fiber diet. Especially, apparent digestibility of fat on a brown rice diet was lower. Dietary fiber delayed digestion by decreasing the surface areas of nutrients that were exposed to hydrolytic enzymes and by inhibiting activity of enzymes (22). Furthermore, dietary fiber did not only affect the intraluminal effects of fiber but also rather affect the changes in the intestinal mucosa induced by ingestion of fiber. These changes included alteration in length, weight and modification in the morphology of the microvilli at the light and electron microscopic levels $(22,23)$. It was suggested that the function of the intestinal absorptive epithelial cells were depressed.

Apparent digestibility of nitrogen of the brown rice diet was lower than that of the polished rice diet, but nitrogen balance was the same. Sugimoto (11) and Merill and Watt (12) reported a decrease of apparent digestibility of nitrogen on brown rice more than 30 years ago. But at that time, the concept of dietary fiber had not been established. They did not discuss the effect of dietary fiber.

When the level of protein intake was adequate, dietary fiber did not affect nitrogen balance (21). But dietary fiber might affect nitrogen balance when protein intake was not adequate (24). People in Western countries take much protein. If these people consume much dietary fiber, increased losses of energy, nitrogen and fat are probably of little consequence. But these losses may be important in countries where the amount of food intake is small and the level of fiber intake is high. Care should be taken to maintain an adequate protein intake when there is a large amount of fiber in the diet.

We expected that the plasma cholesterol level would decrease when a brown rice diet was consumed. In fact, total cholesterol and HDL cholesterol levels with the brown rice diet were not significantly different from those with the polished rice diet. One reason might be that the total cholesterol concentration of our subjects was in the lower part of the normal range. We do not know what effects, if any, a brown rice diet would have on the cholesterol level of a person whose cholesterol level was high. Although there were many experiments in animals about the effect of the dietary fiber on the plasma cholesterol level, it is not known if cellulose and hemicellulose decrease the blood cholesterol level, but on the other hand pectin lowers the plasma lipid level (25). In our experiment, the excretion of lipids in feces increased with the brown rice diet and the plasma lipid level did not vary. The decrease in the apparent digestibility of fat may be helpful to person attempting to reduce body weight and intake of dietary fat.

Our findings indicate that rice fiber had effects like those of wheat fiber in increasing the fecal weight and the excretion of energy, fat and protein. However, rice fiber did not reduce the plasma lipid levels. The definite amount of fiber was necessary to maintain healthful effects on bowel functions and to contribute to

Vol. 32, No. 6, 1986 
prevention of colon cancer in advanced countries. It is generally said that brown rice has many trace elements. We did not determine absorption of trace elements, but from our findings it is supposed that they might decrease too. Further experiments are needed to clarify this.

The authors thank Miss Konomi Ishii, Miss Yuka Osugi, and Miss Masami Tomeda of Osaka City University for their assistance in this study.

\section{REFERENCES}

1) Burkitt, D. P. (1971): Epidemiology of cancer of the colon and rectum. Cancer, 28, 3-31.

2) Burkitt, D. P., Walker, A. R. P., and Painter, N. S. (1972): Effect of dietary fiber on stools and transit times, and its role in the causation of disease. Lancet, II, 1408-1412.

3) Trowell, H. C. (1972): Ischmic heart disease and dietary fiber. Am. J. Clin. Nutr., 25, 926-932.

4) Trowell, H. C. (1975): Dietary-fiber hypothesis of the etiology of diabetes mellitus. Diabetes, 24, 762.

5) Walker, A. R. P., Walker, B. F., Richardson, B. D., and Woolford, A. (1973): Appendicitis, fiber intake and bowl behavior in ethnic groups in South Africa. Postgrad. Med. J., 49, 243-249.

6) Cummings, J. H. (1982): Consequences of the metabolism of fiber in the human large intestine, in Dietary Fiber in Health and Disease, ed. by Vahouny, G. V., and Kritchevsky, D., Plenum, New York, pp. 9-22.

7) Eastwood, M. A., Kirkpatrick, J. R., Mitchell, W. D., Bone, A., and Hamilton, T. (1973): Effects of dietary supplements of wheat bran and cellulose on feaces and bowel function. Br. J. Nutr., 41, 477-485.

8) Southgate, D. A. T., Branch, W. J., and Hill, M. J. (1976): Metabolic responses to dietary supplements of bran. Metabolism, 25, 1129-1135.

9) Cummings, J. H., Hill, M. J., Jenkins, D. J. A., Pearson, J. R., and Wiggims, H. S. (1976): Changes in fecal composition and colonic function due to cereal fiber. Am. J. Clin. Nutr., 29, 1468-1473.

10) Dokkum, W. V., Pikaar, N. A., and Thissen, J. T. N. M. (1983): Physiological effects of fiber-rich types of bread. 2. Dietary fibre from bread: digestibility by the intestinal microflora and water-holding capacity in the colon of human subjects. Br. J. Nutr., $\mathbf{5 0}$, $61-74$.

11) Sugimoto, K. (1926): Relationship between grade of polish and digestibility of rice. Eiyokenkyusho Hokoku (in Japanese), 1, 1-151.

12) Merill, A. L., and Watt, B. K. (1955): Energy Value of Foods, Agricultural Handbook, No. 74, Human Nutrition Research Branch, Agricultural Research Series, United States Depertment of Agriculture, Washington, D. C.

13) Van Soest, P. J., and Wine, R. H. (1967): Use of detergents in the analysis of fibrous feeds. IV. Determination of plants cell-wall constituents. J. Assoc. Offic. Anal. Chem., 50, 50-55.

14) Folch, J., Lees, M., and Stanley, G. H. S. (1957): A simple method for the isolation and purification of total lipids from animal tissues. J. Biol. Chem., 226, 497-509.

15) Allain, C. C., Poon, L. S., Gchan, C. S. G., Richmond, W., and Fu, P. C. (1974): Enzymatic determination of total serum cholesterol. Clin. Chem., 20, 470-475. 
16) Steele, B. W., Koehler, D. F., Azar, M. M., Blaszkowski, T. P., Kuba, K., and Dempsey, M. E. (1976): Enzymatic determinations of cholesterol in high density lipoprotein fractions prepared by a precipitation technique. Clin. Chem., 22, 98-101.

17) Kelsay, J. L. (1978): A review of research on effects of fiber intake on man. Am. J. Clin. Nutr., 31, 142-159.

18) Eastwood, M. A., and Kay, R. M. (1979): An hypothesis for the action of dietary fiber along the gastrointestinal tract. Am. J. Clin. Nutr., 32, 364-367.

19) Stephen, A., and Cumming, J. (1980): Mechanism of action of dietary fiber in human colon. Nature, 284, 283-284.

20) Mitsuoka, T. (1982): Intestinal flora and dietary fiber, in Dietary Fiber (in Japanese), ed. by Innami, T., and Kiriyama, S., Daiitishupan Co., Ltd., Tokyo, pp. 242-270.

21) Kelsay, J. L., Behall, K. M., and Prather, E. S. (1978): Effect of fiber from fruits and vegetables on metabolic responses of human subjects. 1. Bowel transit time, number of defecations, fecal weight, urinary excretions of energy and nitrogen and apparent digestibilities of energy, nitrogen, and fat. Am. J. Clin. Nutr., 31, 1149-1153.

22) Schneeman, B. O. (1982): Pancreatic and digestive function, in Dietary Fiber in Health and Disease, ed. by Vahouny, G. V., and Kritchevsky, D., Plenum, New York, pp. 73-83.

23) Classidy, M. M., Lightfoot, F. G., and Vahouny, G. V. (1982): Morphological aspects of dietary fibers in the intestine. Adv. Lipid Res., 19, 203-229.

24) Kies, C., and Fox, H. (1977): Dietary hemicellulose interactions influencing serum lipid patterns and protein nutritional status of adult men. J. Food Sci., 42, 440-443.

25) Stony, J. A., and Kelley, M. J. (1982): Dietary fiber and lipoproteins, in Dietary Fiber in Health and Disease, ed. by Vahouny, G. V., and Kritchevsky, D., Plenum, New York, pp. 229-238. 